\title{
Relation of upper gastrointestinal bleeding to non-steroidal anti-inflammatory drugs and aspirin: a case-control study
}

\author{
J Holvoet, L Terriere, W Van Hee, L Verbist, E Fierens, M L Hautekeete
}

\begin{abstract}
We conducted a case-control study in five general hospitals in the region of Antwerp, studying 161 patients (102 men, 59 women) and hospital control subjects matched for age and sex to explore the relation between drug use and upper gastrointestinal bleeding from 'erosive lesions' (peptic oesophagitis, gastric erosions, gastric ulcer(s), or duodenal ulcer(s)). There was a highly significant difference between cases and control subjects in the use of non-steroidal anti-inflammatory drugs (NSAIDs, excluding aspirin) (odds ratio $\mathbf{7 \cdot 4}$, $\mathrm{p}<0.001 ; 95 \%$ confidence interval odds ratio 3.7 to 14.7). There also was a significant difference in the use of aspirin (odds ratio $2 \cdot 2$, $p=0.025 ; 95 \% \mathrm{CI}$ odds ratio 1.3 to 4.0 ) and a highly significant difference regarding the presence of antecedents of peptic ulcer disease (odds ratio $5.5, \mathrm{p}<0.001 ; 95 \% \mathrm{CI}$ odds ratio 3.2 to 9.6). There was no significant difference in the use of other drugs, paracetamol and corticosteroids in particular, nor in the use of alcohol or tobacco. The patient group using NSAIDs was older, had more women, and had a higher mortality than the group not using NSAIDs. Among patients with bleeding gastric or duodenal ulcer(s), NSAID users were not more or less likely to have had symptoms of peptic ulcer disease, and had no higher frequency of multiple gastric or duodenal ulcers. The attributable risk for NSAID use was $0.30(95 \% \mathrm{CI} 0.23$ to 0.37$)$ and for aspirin use $0.14(95 \%$ CI 0.08 to $0 \cdot 20)$.
\end{abstract}

Departments of Internal Medicine, Middelheim General Hospital

J Holvoet

M L Hautekeete

Hoge Beuken General Hospital

L Terriere

Stuivenberg General Hospital

W Van Hee

Jan Palfijn General

Hospital

L Verbist

Sint-Erasmus General Hospital

E Fierens

Antwerp, Belgium

Correspondence to: Jan Holvoet, Department of Internal Medicine, Middelheim General Hospital, Lindendreef 1, B-2020 Antwerp, Belgium.

Accepted for publication 10 September 1990
Although the relation between upper gastroin some studies, gastric erosions) and the use of non-steroidal anti-inflammatory drugs (NSAIDs) and aspirin has been extensively studied. ${ }^{1-10}$ the number of well performed casecontrol studies dealing with this subject is limited. ${ }^{3-7}$ Some of these case-control studies concern only aspirin (and paracetamol) ${ }^{3}$ while others comprise only a small number of patients. ${ }^{6-7}$ To reinvestigate the relation between upper gastrointestinal bleeding and drug use, we decided to perform a confirmatory case-control study in five general hospitals in an urban region in Belgium.

\section{Patients and methods}

The trial was a multicentre one, running simultaneously in five general hospitals in and around Antwerp. The hospitals are located in different intestinal bleeding from peptic ulcers (and, parts of the city (centre and outskirts); all serve a predominantly elderly population consisting mostly of people of middle or low income. In each hospital one gastroenterologist was responsible for patient selection, interviewing, and completing the trial forms. From 1 May 1987 to 1 May 1989 all patients admitted to one of the five hospitals because of haematemesis or melaena, or both, were considered for inclusion. For definitive inclusion, the source of bleeding had to be identified by endoscopy performed within 48 hours of admission, and the patient had to have one of the following sources of bleeding: peptic oesophagitis, gastric erosions, gastric ulcer (solitary or multiple), or duodenal ulcer (solitary or multiple). We grouped these lesions under the term 'erosive upper gastrointestinal lesions.' When more than one lesion was present this was recorded on the study form, but the gastroenterologist in charge of the patient had to identify one lesion as the likely source of bleeding. Patients with oesophageal varices, MalloryWeiss syndrome, upper gastrointestinal tract neoplasia, or vascular malformations were excluded from the study. For the control subjects, the next patient admitted to the department of internal medicine of the same hospital matched for sex and age plus or minus 5 years was selected, excluding patients admitted for upper gastrointestinal bleeding or suspicion of upper gastrointestinal bleeding. Cases and control subjects were interviewed using identically structured questionnaires regarding concurrent and previous disease and drug use. Special attention was paid to the presence of symptoms of peptic ulcer disease and the use of analgesic and antiinflammatory drugs such as aspirin, NSAIDs, paracetamol, and corticosteroids. Drug use was considered to be the drugs used in the week before admission. For the cases, the gastroenterologist also had to record the number of units of blood transfused, the type of treatment (medical or surgical), and the outcome (survival or death) on the study form. All study forms were analysed in one centre (Middelheim General Hospital). Drug use was analysed by grouping the drugs in the following categories: aspirin; paracetamol; NSAID (defined as all NSAIDs excluding aspirin); corticosteroids; diuretics; $B$ blocking drugs; other antihypertensives (excluding diuretics and $B$ blocking drugs); antianginous drugs (nitrate derivatives and calcium channel blockers); cardiac glycosides; bronchodilators; antibiotics; psychotropic drugs; oral anticoagulants. When analysing the data, in most instances no distinction was made between patients with solitary or multiple ulcers.

Means (SD) were expressed and compared 
using Student's $t$ test, while absolute numbers were compared using the $\chi^{2}$ test (with Yates's continuity correction). Differences between cases and control subjects with respect to a particular risk factor were evaluated by calculation of the odds ratio (the ratio of discordant pairs), being the number of case-control pairs where a particular factor was present in the case but not in the control, divided by the number of pairs where the factor was not present in the case but present in the control. ${ }^{11}$ The odds ratio provides a good approximation of the relative risk, and both are measures of the degree of association between a factor and an event. ${ }^{12}$ The significance of the odds ratio was calculated by McNemar's $\chi^{2}$ test with continuity correction, ${ }^{11}$ while the confidence interval was calculated using Miettinen's test based approximation." The attributable risk (being an estimation of the proportion of disease directly attributable to a particular factor, in the assumption of causality) was calculated according to the recommendations of Fleiss. ${ }^{12}$ All probability (p) values were two tailed; a $p$ value of 0.05 or less was considered to be significant.

\section{Results}

Of 235 patients considered for inclusion in the study because of upper gastrointestinal bleeding, nine were excluded because data collection was incomplete. Of the remaining 225 patients, 161 proved to have bleeding from 'erosive' upper gastrointestinal lesions. The source of bleeding was peptic oesophagitis in nine $(5 \cdot 6 \%)$, gastric erosions in $12(7 \cdot 4 \%)$, gastric ulcer (solitary or multiple) in $66(41.0 \%)$, and duodenal ulcer (solitary or multiple) in $74(46.0 \%)$. There were 102 male and 59 female patients. Mean (SD) age of cases was $68.0(14.5)$ years (range 19-92) and mean age of control subjects $68 \cdot 1(14 \cdot 5)$ years (range 18-91) (difference not significant by paired $t$ test).

There was no significant difference between cases and control subjects in the use of tobacco, alcohol, paracetamol, corticosteroids, diuretics, $B$ blocking drugs, other antihypertensives, antianginous drugs, cardiac glycosides, bronchodilators, antibiotics, psychotropic drugs, and oral anticoagulants (Table I). There was, however, a highly significant difference in the use of NSAIDs (odds ratio $7 \cdot 4, \mathrm{p}<0.001 ; 95 \%$ confidence interval odds ratio 3.7 to $14 \cdot 7$ ) and a significant difference in the use of aspirin (odds ratio $2 \cdot 2, p=0 \cdot 025 ; 95 \% \mathrm{CI}$ odds ratio $1 \cdot 3$ to $4 \cdot 0$ ) (Table II). There also was a highly significant difference between cases and control subjects regarding the presence of antecedents of peptic ulcer disease (odds ratio 5.5, $\mathrm{p}<0.001 ; 95 \% \mathrm{CI}$ odds ratio $3 \cdot 2$ to $9 \cdot 6$ ) (Table II).

When odds ratios for NSAID use were calculated separately for each source of bleeding and for sex (Table III) they were highly significant both for gastric ulcer(s) and for duodenal ulcer(s) and for both men and women (all $\mathrm{p}<0.001$ ); they were not significant for gastric erosions and oesophagitis.

When patients were grouped according to sex and source of bleeding a significant difference existed for gastric and duodenal ulcer(s) in
TABLE I Factors not significantly different between cases and control subjects ${ }^{\star}$

\begin{tabular}{|c|c|c|c|}
\hline Factor & $\begin{array}{l}\text { Discordant } \\
\text { pairs }\end{array}$ & Odds ratio & $\begin{array}{l}95 \% \\
\text { confidence } \\
\text { interval }\end{array}$ \\
\hline Tobacco & $33 / 30$ & $1 \cdot 1$ & 0.5 to 2.3 \\
\hline Alcohol & $32 / 19$ & 1.7 & 0.9 to 3.2 \\
\hline Paracetamol & $14 / 10$ & $1 \cdot 4$ & 0.5 to 4.1 \\
\hline Corticosteroids & $7 / 17$ & $0 \cdot 4$ & 0.2 to 1.1 \\
\hline Diuretics & $25 / 15$ & $1 \cdot 7$ & 0.8 to 3.5 \\
\hline B blocking drugs & $20 / 10$ & $2 \cdot 0$ & 0.9 to 4.6 \\
\hline Other antihypertensives & $3 / 7$ & 0.4 & 0.1 to 2.7 \\
\hline Anti-anginous drugs & $21 / 15$ & $1 \cdot 4$ & 0.6 to 3.1 \\
\hline Cardiac glycosides & $9 / 13$ & 0.7 & 0.2 to $2 \cdot 1$ \\
\hline Bronchodilators & $13 / 13$ & $1 \cdot 0$ & - \\
\hline Antibiotics & $4 / 7$ & 0.6 & 0.1 to $3 \cdot 2$ \\
\hline Psychotropic drugs & $18 / 13$ & $1 \cdot 4$ & 0.6 to 3.5 \\
\hline Oral anticoagulants & $3 / 5$ & $0 \cdot 6$ & 0.1 to $10 \cdot 1$ \\
\hline
\end{tabular}

* The odds ratio (the ratio of discordant pairs) is the number of case-control pairs where a particular factor was present in the case but not in the control, divided by the number of pairs where the but not in the control, divided by the number of pairs where
factor was not present in the case while it was present in the control. The statistical significance of the odds ratio was calculated by McNemar's $\chi^{2}$ test. ${ }^{\prime \prime}$

Note: None of the $p$ values in this table were significant.

women and for duodenal ulcer(s) in men; the odds ratio for gastric ulcer(s) in men approached significance $(\mathrm{p}=0 \cdot 10)$ (Table III). Odds ratios for people aged 60 or younger and over 60 were compared (Table III), and were highly significant in the older age group $(p<0.001)$, whereas although the difference in younger patients was less significant it was clearly significant $(p=0 \cdot 025)$. When patients were grouped according to age and sex, significance was highest in older women and men, respectively; the difference was less significant in younger men and not found in younger women, probably because of the small number of patients in that group (Table III). When calculations for these different subgroups were repeated for aspirin use (Table IV) only the odds ratio for women was significant; none of the other odds ratios was significant, although they approached significance in older people and both older and younger women $(p=0 \cdot 10)$. Twelve patients were using both NSAIDs and aspirin; the source of bleeding in these patients was duodenal ulcer(s) in six, gastric ulcer(s) in four, gastric erosions in one,

TABLE II Factors significantly different between cases and control subjects ${ }^{\star}$

\begin{tabular}{lccc}
\hline & \multicolumn{2}{c}{ Control } & \\
\cline { 2 - 3 } Case & Used & Not used & Totals \\
\hline NSAID: & 3 & 52 & 55 \\
Used & 7 & 99 & 106 \\
Not used & 10 & 151 & 161
\end{tabular}

Odds ratio $7 \cdot 4, \mathrm{p}<0.01$

$95 \%$ confidence interval odds ratio $3 \cdot 7$ to 14.7

Aspirin:

Used

Total $\begin{array}{rrr}8 & 35 & 43\end{array}$

Odds ratio $2 \cdot 2, \mathrm{p}=0 \cdot 025$

$95 \%$ confidence interval odds ratio $1 \cdot 3$ to $4 \cdot 0$

\begin{tabular}{|c|c|c|c|}
\hline & \multicolumn{2}{|l|}{ Control } & \multirow[b]{2}{*}{ Totals } \\
\hline & Present & Absent & \\
\hline \multicolumn{4}{|c|}{ Symptoms of peptic ulcer disease: } \\
\hline Present & $\begin{array}{r}4 \\
12 \\
16\end{array}$ & $\begin{array}{r}66 \\
79 \\
145\end{array}$ & $\begin{array}{r}70 \\
91 \\
161\end{array}$ \\
\hline
\end{tabular}

Odds ratio $5 \cdot 5, \mathrm{p}<0.001$

$95 \%$ confidence interval odds ratio $3 \cdot 2$ to $9 \cdot 6$

* See footnote to Table 1 . 
TABLE III Odds ratios according to source of bleeding, age (years), and sex for NSAID use*

\begin{tabular}{|c|c|c|c|}
\hline Group & $\begin{array}{l}\text { Discordant } \\
\text { pairs }\end{array}$ & $\begin{array}{l}\text { Odds ratio } \\
\text { and p value }\end{array}$ & $\begin{array}{l}95 \% \\
\text { confidence } \\
\text { interval }\end{array}$ \\
\hline All cases (Table II) & $52 / 7$ & $7 \cdot 4, p<0.001$ & $3 \cdot 7$ to $14 \cdot 7$ \\
\hline $\begin{array}{l}\text { Oesophagitis } \\
\text { Gastric erosions } \\
\text { Gastric ulcer(s) } \\
\text { Duodenal ulcer(s) }\end{array}$ & $\begin{array}{r}2 / 0 \\
6 / 1 \\
18 / 2 \\
26 / 4\end{array}$ & $\begin{array}{l}\text { NS } \\
6, \mathrm{NS} \\
9, \mathrm{p}<0.001 \\
6.5, \mathrm{p}<0.001\end{array}$ & $\begin{array}{l}- \\
0.6 \text { to } 61 \cdot 2 \\
2.5 \text { to } 32.5 \\
2.5 \text { to } 16.9\end{array}$ \\
\hline $\begin{array}{l}\text { Age } \leqslant 60 \\
\text { Age }>60\end{array}$ & $\begin{array}{l}10 / 1 \\
42 / 6\end{array}$ & $\begin{array}{l}10, p=0.025 \\
7, p<0.001\end{array}$ & $\begin{array}{l}1.5 \text { to } 64.6 \\
3.3 \text { to } 14.9\end{array}$ \\
\hline $\begin{array}{l}\text { Men: } \\
\text { All men } \\
\text { Age } \leqslant 60 \\
\text { Age }>60 \\
\text { Oesophagitis } \\
\text { Gastric erosions } \\
\text { Gastric ulcer(s) } \\
\text { Duodenal ulcer(s) }\end{array}$ & $\begin{array}{r}27 / 4 \\
8 / 1 \\
19 / 3 \\
2 / 0 \\
3 / 0 \\
9 / 2 \\
13 / 2\end{array}$ & $\begin{array}{l}6 \cdot 7, p<0 \cdot 001 \\
8, p=0 \cdot 05 \\
6 \cdot 3, p=0 \cdot 005 \\
2, N S \\
\text { NS } \\
4 \cdot 5, N S(p=0 \cdot 10) \\
6 \cdot 5, p=0 \cdot 01\end{array}$ & $\begin{array}{l}2.6 \text { to } 17.4 \\
1.0 \text { to } 61.4 \\
2.0 \text { to } 20.1 \\
- \\
- \\
0.9 \text { to } 22.8 \\
1.6 \text { to } 28 \cdot 1\end{array}$ \\
\hline $\begin{array}{l}\text { Women: } \\
\text { All women } \\
\text { Age } \leqslant 60 \\
\text { Age }>60 \\
\text { Oesophagitis } \\
\text { Gastric erosions } \\
\text { Gastric ulcer(s) } \\
\text { Duodenal ulcer(s) }\end{array}$ & $\begin{array}{r}25 / 3 \\
2 / 0 \\
23 / 3 \\
0 / 0 \\
3 / 0 \\
9 / 0 \\
13 / 2\end{array}$ & $\begin{array}{l}8.3, \mathrm{p}<0.001 \\
\text { NS } \\
7.7, \mathrm{p}<0.001 \\
\text { NS } \\
3, \mathrm{NS} \\
\mathrm{p}=0.01 \\
6.5, \mathrm{p}=0.01\end{array}$ & $\begin{array}{l}2 \cdot 9 \text { to } 23 \cdot 7 \\
2 \cdot 6 \text { to } 22 \cdot 6 \\
- \\
- \\
1 \cdot 6 \text { to } 28 \cdot 1\end{array}$ \\
\hline
\end{tabular}

^ See footnote to Table I.

NS=not significant.

and oesophagitis in one. The attributable risk for NSAID use was $0.30(95 \%$ CI 0.23 to 0.37$)$ and for aspirin use 0.14 (95\% CI 0.08 to 0.20$)$; when only patients with bleeding peptic ulcer(s) were considered, these figures were, respectively, $0.29(0.21$ to 0.37$)$ and $0.12(0.06$ to 0.18$)$.

Patients using NSAIDs were older than patients not using them (mean (SD) age $71 \cdot 3$ $(13.4)$ years, range $33-89 v 66 \cdot 1(14.8)$ years, range $19-92 ; p=0.05)$. The sex distribution was also different in the two groups (patients using NSAIDs: 27 men, 28 women; patients not using NSAIDs: 75 men, 31 women; $p=0.025$ ). Of the NSAID users, $15(27 \cdot 3 \%)$ used piroxicam, $10(18 \cdot 2 \%)$ diclofenac, $7(12 \cdot 7 \%)$ naproxen, 5 $(9 \cdot 1 \%)$ indomethacin, $4(7 \cdot 3 \%)$ sulindac, 2 (3.6\%) ibuprofen, and $12(21 \cdot 8 \%)$ another

TABLE IV Odds ratios according to source of bleeding, age (years), and sex for aspirin use

\begin{tabular}{|c|c|c|c|}
\hline Group & $\begin{array}{l}\text { Discordant } \\
\text { pairs }\end{array}$ & $\begin{array}{l}\text { Odds ratio } \\
\text { and p value }\end{array}$ & $\begin{array}{l}95 \% \\
\text { confidence } \\
\text { interval }\end{array}$ \\
\hline All cases (Table II) & $35 / 16$ & $2 \cdot 2, p=0.025$ & $1 \cdot 3$ to 4.0 \\
\hline $\begin{array}{l}\text { Oesophagitis } \\
\text { Gastric erosions } \\
\text { Gastric ulcer(s) } \\
\text { Duodenal ulcer(s) }\end{array}$ & $\begin{array}{l}1 / 0 \\
5 / 1 \\
19 / 11 \\
10 / 4\end{array}$ & $\begin{array}{l}\text { NS } \\
5, \mathrm{NS} \\
1 \cdot 7, \mathrm{NS} \\
2 \cdot 5, \mathrm{NS}\end{array}$ & $\begin{array}{l}\overline{0.4} \text { to } 65.7 \\
0.7 \text { to } 3.8 \\
0.7 \text { to } 9.6\end{array}$ \\
\hline $\begin{array}{l}\text { Age } \leqslant 60 \\
\text { Age }>60\end{array}$ & $\begin{array}{l}12 / 5 \\
23 / 11\end{array}$ & $\begin{array}{l}2 \cdot 4, N S \\
2 \cdot 1, N S(p=0 \cdot 10)\end{array}$ & $\begin{array}{l}0.7 \text { to } 7.8 \\
1.0 \text { to } 4.5\end{array}$ \\
\hline $\begin{array}{l}\text { Men: } \\
\text { All men } \\
\text { Age } \leqslant 60 \\
\text { Age }>60 \\
\text { Oesophagitis } \\
\text { Gastric erosions } \\
\text { Gastric ulcer(s) } \\
\text { Duodenal ulcer(s) }\end{array}$ & $\begin{array}{l}17 / 11 \\
7 / 5 \\
10 / 6 \\
1 / 1 \\
2 / 0 \\
9 / 8 \\
5 / 3\end{array}$ & $\begin{array}{l}1 \cdot 5, \text { NS } \\
1 \cdot 4, \text { NS } \\
1 \cdot 7, \text { NS } \\
1, \text { NS } \\
\text { NS } \\
1 \cdot 1, \text { NS } \\
1 \cdot 7, \text { NS }\end{array}$ & $\begin{array}{l}0.7 \text { to } 3.5 \\
0.1 \text { to } 13.8 \\
0.4 \text { to } 6.8 \\
- \\
- \\
\overline{0} \\
0.1 \text { to } 32.1\end{array}$ \\
\hline $\begin{array}{l}\text { Women: } \\
\text { All cases } \\
\text { Age } \leqslant 60 \\
\text { Age }>60 \\
\text { Oesophagitis } \\
\text { Gastric erosions } \\
\text { Gastric ulcer(s) } \\
\text { Duodenal ulcer(s) }\end{array}$ & $\begin{array}{r}18 / 5 \\
5 / 0 \\
13 / 5 \\
0 / 0 \\
3 / 1 \\
10 / 3 \\
5 / 1\end{array}$ & $\begin{array}{l}3 \cdot 6, p=0 \cdot 025 \\
\text { NS }(p=0 \cdot 10) \\
2 \cdot 6, N S(p=0 \cdot 10) \\
\text { NS } \\
3, \text { NS } \\
\text { 3.3, NS } \\
5, \text { NS }\end{array}$ & $\begin{array}{l}1.3 \text { to } 9.8 \\
-=.8 \text { to } 8.1 \\
-0.04 \text { to } 222 \\
0.5 \text { to } 24.1 \\
0.4 \text { to } 65.7\end{array}$ \\
\hline
\end{tabular}

NSAID; of the control patients $3(30 \%)$ used diclofenac, $3(30 \%)$ indomethacin, $2(20 \%)$ naproxen, 1 (10\%) piroxicam, and $1(10 \%)$ another NSAID; differences between cases and control subjects were not significant. Transfusion requirements were not significantly different between patients using NSAIDs and those not using them (mean (SD) number of units of blood transfused in patients using NSAIDs 4.5 $(7 \cdot 5)$ units, range $0-44 v 3.9(5 \cdot 1)$ units, range $0-41$; not significant), nor was there a difference in the requirement of surgical treatment (patients using NSAIDs needing surgery: seven of 55 $(12.7 \%) v 11$ of $106(10.4 \%)$, not significant). On the other hand, there was a difference in outcome between the two groups: in the group using NSAIDs eight of $55(14.5 \%)$ patients died while four of $106(3.8 \%)$ patients not using NSAIDs died; $p=0.025$. When outcome was correlated with age by dividing the patient population into four age groups (Table V) the mortality of NSAID users was higher than that of non-users both for the group of patients aged 60 79 years and for the group of patients aged over 80 years; however, the observed differences were not significant, although one of the $p$ values approached significance (Table V). In the 140 patients with bleeding gastric or duodenal ulcer(s), the presence of symptoms of peptic ulcer disease was not different in patients using NSAIDs (symptoms of peptic ulcer disease were present in 23 of the 47 NSAID users (48.9\%) and in 44 of the 93 cases not using NSAIDs (47.3\%), not significant), nor were multiple gastric or duodenal ulcers more (or less) frequent in patients using NSAIDs (gastric ulcer: nonNSAID users $38(82.6 \%)$ with a solitary ulcer eight $(17 \cdot 4 \%)$ with multiple ulcers; NSAID users $17(85 \%)$ with a solitary ulcer, three (15\%) with multiple ulcers: not significant; duodenal ulcer: non-NSAID users $41(87 \cdot 2 \%)$ with a solitary ulcer, six $(12 \cdot 8 \%)$ with multiple ulcers; NSAID users $19(70.4 \%)$ with a solitary ulcer, eight $(29.6 \%)$ with multiple ulcers, not significant).

Duration of intake of NSAIDs and aspirin and dose of aspirin for cases and control subjects are summarised in Table VI; none of the differences between cases and control subjects were significant. In 24 patients more than one lesion was seen; the different combinations and their relation to aspirin and NSAID use were: duodenal and gastric ulcer(s) in eight (five patients using NSAIDs, two of whom also used aspirin); duodenal ulcer(s) and gastric erosions in four (three patients using NSAIDs); gastric ulcer(s) and erosions in two (one using NSAIDs); duodenal ulcer(s) and oesophagitis in four (two using NSAIDs); gastric ulcer(s) and oesophagitis in three (two using NSAIDs); and gastric erosions and oesophagitis in three (two using aspirin).

\section{Discussion}

Our study confirms the highly significant association between upper gastrointestinal bleeding from 'erosive' lesions and NSAID use reported in earlier case-control studies. ${ }^{467} \mathrm{We}$ found that the association was highly significant for both men and women and for older patients, particularly 
TABLE V Outcome according to patient age and NSAID use

\begin{tabular}{|c|c|c|c|c|c|}
\hline \multirow[b]{2}{*}{ NSAID use } & \multicolumn{5}{|c|}{ Age (years) } \\
\hline & $<40$ & $40-59$ & $60-79$ & $>80$ & Total \\
\hline $\begin{array}{l}\text { Non-users: } \\
\text { Died } \\
\text { Survived } \\
\% \text { dying }\end{array}$ & $\begin{array}{l}\overline{8} \\
0 \%\end{array}$ & ${ }_{0 \%}^{\overline{26}}$ & $\begin{array}{l}1 \\
49 \\
2 \cdot 0 \%\end{array}$ & $\begin{array}{l}3 \\
19 \\
13 \cdot 6 \%\end{array}$ & $\begin{array}{l}102 \\
3 \cdot 8 \%\end{array}$ \\
\hline $\begin{array}{l}\text { Users: } \\
\text { Died } \\
\text { Survived } \\
\text { \% dying }\end{array}$ & $\begin{array}{l}\overline{2} \\
0 \%\end{array}$ & $\begin{array}{l}- \\
8 \\
0 \%\end{array}$ & $\begin{array}{l}3 \\
24 \\
11 \cdot 1 \%\end{array}$ & $\begin{array}{l}5 \\
13 \\
27 \cdot 8 \%\end{array}$ & 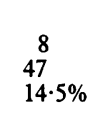 \\
\hline p valuest & NS & NS & NS $(p=0.10)$ & NS & 0.025 \\
\hline
\end{tabular}

$\star$ Expressed as percentage of total number of patients in age and user or non-user group. †Comparing mortality of NSAID users and non-NSAID users for each age group; $\chi^{2}$ test. NS $=$ not significant. older women. This has been described ${ }^{4}$ and can be explained at least in part by the fact that this group of patients consumes the largest number of NSAIDs. ${ }^{2}$ The difference regarding NSAID use was also highly significant for both gastric and duodenal ulcer(s). It is known that NSAID use is associated more with gastric ulcers than with duodenal ulcers, ${ }^{1210}$ and in our study odds ratios for the whole population and for women were higher for bleeding gastric ulcers than duodenal ulcer(s); these results are comparable to those reported earlier. ${ }^{4}$ Nevertheless, confidence intervals widely overlap, confirming the broad assessment that the risk is roughly comparable for each site. $^{2}$

Patients with upper gastrointestinal bleeding from 'erosive' lesions associated with NSAID use were older than patients who were non-users of NSAIDs, and in the user group both sexes were equally represented, whereas in non-users there was an important male predominance. This has been a feature of several other studies ${ }^{61314}$ and probably reflects prescribing habits. Another striking finding was the difference in outcome for NSAID users, whereas there was no significant difference in transfusion requirements or need for surgery. In some studies concerning NSAID use and upper gastrointestinal bleeding no difference was found in the need for surgical treatment or in mortality, ${ }^{14}$ whereas in others a significant difference in transfusion requirements was found. ${ }^{15}$ An update of the spontaneous reporting of adverse reactions in the United Kingdom also suggested that adverse reactions to NSAIDs are more likely to be fatal in older patients. ${ }^{16}$ In two studies of the relation between NSAID use and life threatening complications of peptic ulceration (bleeding or perforation) one study reported a striking difference in outcome, ${ }^{13}$ but another

TABLE VI Duration of intake of NSAID and aspirin and dose of aspirin in cases and control subjects * (Percentages in parentheses)

\begin{tabular}{|c|c|c|c|c|}
\hline & \multicolumn{2}{|l|}{$N S A I D$} & \multicolumn{2}{|l|}{ Aspirin } \\
\hline & Case & Control & Case & Control \\
\hline $\begin{array}{l}\text { Duration: } \\
\text { Less than } 1 \text { week } \\
1 \text { week }-1 \text { month } \\
1 \text { month - } 1 \text { year } \\
\text { More than } 1 \text { year } \\
\text { Duration unknown }\end{array}$ & $\begin{array}{c}15(27 \cdot 3) \\
15(27 \cdot 3) \\
16(29 \cdot 0) \\
9(16 \cdot 4) \\
0(0)\end{array}$ & $\begin{array}{l}3(30) \\
2(20) \\
2(20) \\
2(20) \\
1(10)\end{array}$ & $\begin{array}{c}10(23 \cdot 2) \\
10(23 \cdot 2) \\
5(11 \cdot 6) \\
15(34 \cdot 9) \\
3(7 \cdot 0)\end{array}$ & $\begin{array}{c}5(20 \cdot 8) \\
5(20.8) \\
4(16.8) \\
10(41 \cdot 7) \\
0(0)\end{array}$ \\
\hline $\begin{array}{l}\text { Dose: } \\
\text { Less than } 2 \mathrm{~g} \text { a week } \\
\text { More than } 2 \mathrm{~g} \text { a week }\end{array}$ & - & $\overline{-}$ & $\begin{array}{l}21(48 \cdot 8) \\
22(51 \cdot 2)\end{array}$ & $\begin{array}{l}11(45 \cdot 8) \\
13(54 \cdot 2)\end{array}$ \\
\hline
\end{tabular}

^ Number of cases $/ \%$ of patients taking the drug. could not confirm this. ${ }^{17}$ It is difficult to conclude from our study whether the difference in outcome we found is merely a reflection of the patient's more advanced age, as differences in outcome existed for both the 60-79 age group and the over 80 age group but were only significant for the patient population as a whole (Table V). Nothing can be reported for younger patients in our study because of the relatively small number of patients in these age groups and the absence of fatal cases.

In most studies, as in ours, there was no clear difference in the risk associated with a particular NSAID. ${ }^{46718}$ There was also no clear relation between duration of intake and occurrence of bleeding, as is the case in most studies. ${ }^{2}$ Finally, it is not known whether NSAID associated ulcers are caused entirely by NSAIDs or represent an exacerbation by NSAIDs of pre-existing ulcers, or of an underlying 'peptic diathesis'.' Our finding that the characteristics of bleeding ulcers associated with NSAID use (as regards the presence of symptoms of peptic ulcer disease and the multiplicity of lesions) are not different from those not associated with NSAID use is a relative argument in favour of the hypothesis that there is no fundamental difference between ulcers associated with NSAIDs and those not associated with NSAIDs. Another smaller study has already found no significant difference concerning symptoms of peptic ulcer disease in patients with NSAID or aspirin associated upper gastrointestinal bleeding. ${ }^{6}$

Concerning aspirin use we could only find a significant difference between cases and control subjects for the whole population and for women, with no clear relation between dose or duration of intake. Our data are roughly in accordance with the findings of an earlier casecontrol studys and confirm the conclusion that although the relation between aspirin use and upper gastrointestinal bleeding certainly exists, aspirin is of lesser importance than NSAID.

There was no significant difference in the use of other drugs, paracetamol and corticosteroids in particular. Only one case-control study found an association between upper gastrointestinal bleeding and recent, but not longterm paracetamol exposure ${ }^{3}$; others found no association at all.' Whether corticosteroids can cause peptic ulcers is still controversial'; their role in the induction of upper gastrointestinal bleeding, if present at all, is very small. ${ }^{20}$ The fact that no other types of drugs are significantly associated with upper gastrointestinal bleeding is in accordance with other case-control studies ${ }^{+}$; it is noteworthy that oral anticoagulants were not significantly associated with upper gastrointestinal bleeding in our study or in others. ${ }^{9}$

In our.study, neither the use of alcohol nor the use of tobacco was significantly associated with upper gastrointestinal bleeding from 'erosive' lesions. Alcohol and tobacco use were not significantly associated with upper gastrointestinal bleeding in most published case-control studies. $^{3+6}$

Our finding of the highly significant association of upper gastrointestinal bleeding with the presence of peptic ulcer disease confirm the notion that symptoms of peptic ulcer disease are a 
risk factor for the development of peptic ulcer disease complications, in non-NSAID users as well as in NSAID-users. ${ }^{2}$ Nevertheless, among the 140 patients with bleeding peptic ulcer(s), bleeding was the first sign of peptic ulcer disease in $69(52 \cdot 2 \%)$; the absence of signs of peptic ulcer disease in a high proportion of patients with peptic ulcer complications has been reported repeatedly in recent years. ${ }^{13}$

Finally, the attributable risk we found for NSAID use is somewhat higher than the figure reported by Somerville and colleagues, ${ }^{4}$ but the confidence intervals overlap; the attributable risk for aspirin in our study was nearly identical to the one reported by the same group. ${ }^{5}$ When we take into account that some patients were using NSAIDs and aspirin, our data are in accordance with the view that over one third of all haemorrhages from peptic ulcers can be attributed to NSAID or aspirin use. ${ }^{5}$

Some issues that concern the validity of our study should be discussed. In the participating hospitals a very high proportion of eligible subjects was included. We wish to mention, however, that the five participating hospitals cover only about half of the population of Antwerp; our data cannot be interpreted as being representative of the patient population of the whole city area. Another issue concerns the selection of control subjects. We went to great lengths to ascertain that the hospital control subjects were relevant, as stated above, and we believe that our control group was a well matched group. We have, however, not used community controls; this implies that some of our results should be interpreted with caution, particularly those concerning alcohol and tobacco use. Finally, our inclusion of patients with peptic oesophagitis and gastric erosions in the study can be criticised. We decided to include these patients because NSAIDs have been linked to peptic oesophagitis ${ }^{21}$ and because of the well known effect of aspirin (and, to a lesser extent, NSAIDs) to induce mucosal erosions by local irritation. ${ }^{2}$ For gastric erosions we found high odds ratios for both NSAIDs and aspirin, but the associations were not significant, probably because of the small number of patients with bleeding at this site. For oesophagitis odds ratios were low and not significant. It should be reiterated that the number of patients with two of these diagnoses was small; their inclusion in the patient population does not change any of the overall conclusions of the study.

We conclude that, in our study, NSAID use and the presence of symptoms of peptic ulcer disease were the major factors associated with upper gastrointestinal bleeding from 'erosive' lesions. We and others ${ }^{467}$ found a high relative risk for NSAID use, but it should be noted that the absolute individual risk is probably low.' Nevertheless, as pointed out, the number of cases induced in the whole population becomes important in view of the widespread use of NSAIDs. ${ }^{124}$

We are indebted to Leon Kaufman for his help in the statistical analysis of the study.

1 Langman MJS. Epidemiologic evidence on the association between peptic ulceration and anti-inflammatory drug use. Gastroenterology 1989; 96: 640-6.

2 Soll AH. Pathogenesis of peptic ulcer and implications for therapy. N Engl f Med 1990; 322: 909-16.

3 Coggon D, Langman MJS, Spiegelhalter D. Aspirin, paracetamol, and haematemesis and melaena Gut 1982; 23: $340-4$.

4 Somerville K, Faulkner G, Langman M. Non-steroidal antiinflammatory drugs and bleeding peptic ulcer. Lancet 1986 i. $462-4$

5 Faulkner G, Prichard P, Somerville K, Langman MJS Aspirin and bleeding peptic ulcers in the elderly. BMF 1988 297: 1311-3.

6 Bartle WR, Gupta AK, Lazor J. Nonsteroidal antiinflammatory drugs and gastrointestinal bleeding: a casecontrol study. Arch Intern Med 1986; 146: 2365-7.

7 Levy M, Miller DR, Kaufman DW, et al. Major upper gastrointestinal tract bleeding: relation to the use of aspirin and other non-narcotic analgesics. Arch Intern Med 1988; 148: $281-5$.

8 Levy M. Aspirin use in patients with major upper gastrointestinal bleeding and peptic-ulcer disease: a report from the Boston Collaborative Drug Surveillance Program, Bosthe Boston Collaborative Drug Surveillance Program, Boston Univers.

9 Carson JL, Strom BL, Soper KA, West SL, Morse ML. The association of non-steroidal anti-inflammatory drugs with upper gastrointestinal tract bleeding. Arch Intern Med 1987; 147: $85-8$.

10 Duggan JM, Dobson AJ, Johnson H, Fahey P. Peptic ulcer and non-steroidal anti-inflammatory agents. Gut 1986; 27 : 929-33.

11 Kirkwood BR. Essentials of medical statistics. Oxford: Blackwell Scientific, 1988: 179-83.

12 Fleiss JL. Statistical methods for rates and proportions. 2nd ed. New York: Wiley, 1981: 75-82.

13 Armstrong CP, Blower AL. Non-steroidal anti-inflammatory drugs and life threatening complications of peptic ulceration. Gut 1987; 28: 527-32.

14 Duhamel C, Czernichow P, Dechelotte P, Ducrotte P, Lerebours E, Colin R. Upper gastrointestinal hemorrhage caused by anti-inflammatory agents. Gastroenterol Clin Biol $1989 ; 13: 239-44$

15 DeBoer SY, VanBerge-Henegouwen GP, Kluitman EM. Nonsteroidal anti-inflammatory drugs and bleeding gastric and duodenal ulcers. Ned Tijdscher Geneeskd 1988; 132: 160-3.

16 Committee on Safety of Medicines Update. Non-steroidal antiinflammatory drugs and serious gastrointestinal adverse reactions - 1. BMF 1986; 292: 614 .

17 Henry DA, Johnston A, Dobson A, Duggan J. Fatal peptic ulcer complications and the use of non-steroidal antiinflammatory drugs, aspirin, and corticosteroids. $B M \mathcal{F}$ 1987; 295: 1227-9.

18 Biour M, Blanquart A, Moore N, et al. Incidence of NSAIDrelated, severe gastrointestinal bleeding. Lancet 1987; ii: related,

19 Conn HO, Poynard T. Adrenocorticosteroid administration and peptic ulcer: a critical analysis. $\mathcal{F}$ Chronic Dis 1985; 38: 457-68.

20 Bianchi Porro G, Pace F. Ulcerogenic drugs and upper gastrointestinal bleeding. Clinico in Gastroenterology 1988; 2: 309-27.

21 Heller SR, Fellows IW, Ogilvie AL, Atkinson M. Nonsteroidal anti-inflammatory drugs and benign oesophageal stricture. $B M F$ 1982; 285: 167-8. 